\title{
Two Forms of Electrical Transmission Between Neurons
}

\author{
Donald S. Faber ${ }^{1,2}$ and Alberto E. Pereda ${ }^{1,2 *}$ \\ ${ }^{1}$ Dominick P. Purpura Department of Neuroscience, Albert Einstein College of Medicine, New York, NY, United States, \\ ${ }^{2}$ Marine Biological Laboratory, Woods Hole, MA, United States
}

Electrical signaling is a cardinal feature of the nervous system and endows it with the capability of quickly reacting to changes in the environment. Although synaptic communication between nerve cells is perceived to be mainly chemically mediated, electrical synaptic interactions also occur. Two different strategies are responsible for electrical communication between neurons. One is the consequence of low resistance intercellular pathways, called "gap junctions", for the spread of electrical currents between the interior of two cells. The second occurs in the absence of cell-to-cell contacts and is a consequence of the extracellular electrical fields generated by the electrical activity of neurons. Here, we place present notions about electrical transmission in a historical perspective and contrast the contributions of the two different forms of electrical communication to brain function.

Keywords: synaptic communication, electrical synapse, gap junction, electric field, ephapsis

\section{INTRODUCTION}

OPEN ACCESS

Edited by:

Juan Andrés Orellana, Pontificia Universidad Católica de

Chile, Chile

Reviewed by:

Christian Broberger, Karolinska Institutet (KI), Sweden

Lidia Szczupak,

Universidad de Buenos Aires, Argentina

*Correspondence: Alberto E. Pereda alberto.pereda@einstein.yu.edu

Received: 23 July 2018 Accepted: 05 November 2018 Published: 21 November 2018

Citation: Faber DS and Pereda AE (2018) Two Forms of Electrical Transmission Between Neurons. Front. Mol. Neurosci. 11:427. doi: 10.3389/fnmol.2018.00427
It has been argued that the function of the nervous system is to support movement and that it evolved because of its usefulness to organisms in navigating their environment (Llinás, 2001). Early observations established that nerves were required for muscle contraction. However, the mechanism underlying this interaction was unknown. An old, predominant, idea embraced by Rene Descartes was that muscle contraction resulted from the action of "animal spirits" running through hollow nerves (Piccolino, 1998; Finger, 2005). This and other speculative ideas were later disproved, leading to the consideration of alternative mechanisms. One of them was electricity (Franklin, 1751). The use of electricity for therapeutic purposes was popular in the second part of the 18th century, and electricity was capable of eliciting muscle contraction. In addition, because of its high travel velocity, electricity was ideally suited to be the agent responsible for nerve action, as some hypothesized (Finger, 2005). Furthermore, experimental evidence showed that certain fish were capable of generating electricity. All this preceding work and speculations paved the way to the studies conducted by Galvani (1791) which demonstrated that nerves and muscles generate electricity ("bioelectricity") and, therefore, that electricity was the mysterious fluid or "animal spirit" responsible for nerve conduction and muscle contraction (Piccolino, 1998; Finger, 2005). We know now that these electrical currents result from the movement of charged ions across the cellular membrane following their electrochemical gradient (Hodgkin and Huxley, 1952; Armstrong, 2007). Galvani's seminal studies led to the foundation of electrophysiology and to the discovery that brain function and, hence, animal behavior, depends upon electrophysiological computations, the only operational mode fast enough to support the required time frame of decision making by neural circuits. In other words, as emphasized by Llinás, electricity makes us who we are (Sohn, 2003). 
The discovery that the brain is constructed from networks of individual cells that generate electrical signals raised the question of how electrical currents "jump" from one cell to another. The most hotly debated question in Neuroscience during the 20th century was whether synaptic transmission, which is the currency of the brain, is mediated electrically or chemically. In fact, this might have been the major point of dispute in the biological sciences in that era, with advocates on both sides avidly defending their positions with data-based and theoretical models. Each side advanced its favored mechanism on the basis of its assumed advantages for the operation of neural networks in the central nervous system (CNS). Thus, a great deal of effort was devoted to determining whether there was a delay of 1-2 ms between a presynaptic action potential and the start of a postsynaptic response (chemical) or not (electrical), and to the corresponding functional consequences of these alternatives. In this review article, we briefly describe the critical elements of the debate between electrical and chemical modes of transmission, which seemed to tilt strongly in favor of the latter once it emerged that synaptic inhibition in the spinal cord was mediated by an ionic conductance change. This was particularly compelling in view of the difficulties in determining a satisfying mechanism for electrical inhibition. However, in recent years, electrical transmission has regained recognition and relevance. Rather than occurring via a single mechanism, electrical transmission operates in two ways: via pathways of low resistance between neurons (gap junctions) or as a consequence of extracellular electric fields generated by neuronal activity. Thus, we focus not only on the differences between these modes of operation, but also on the concept they share some operational characteristics. Far from providing an extensive review on the topic, we center here on a number of classic and recent examples that we believe illustrate these properties.

\section{THE SEARCH FOR THE MECHANISMS OF SYNAPTIC TRANSMISSION}

The question of whether transmission between neurons is mediated electrically or chemically (Figure 1A) was posed formally in the 1870 s, when the prevailing view of the nervous system was that it was a syncytium of connected nodes within a reticular structure. As stated by Eccles (Eccles, 1982), "It was an obvious conjecture that transmission between two electrically generating and responsive structures could be electrical," but there already were experimental data suggesting chemical transmission at the neuromuscular synapse. The distinction between the two modes was clarified in the ensuing decades, with the advent of the neuron doctrine, according to which neurons are independent biological units (reviewed in Eccles, 1961, 1982). Briefly, the preponderance of data obtained at peripheral nervous system junctions was pharmacological and supported the concept of chemical transmission, such as the action of acetylcholine at the heart. However, in the case of the CNS, there wasn't pharmacological data mimicking synaptic action, and the neuronal responses to applied chemical agents had longer delays than those of the responses evoked

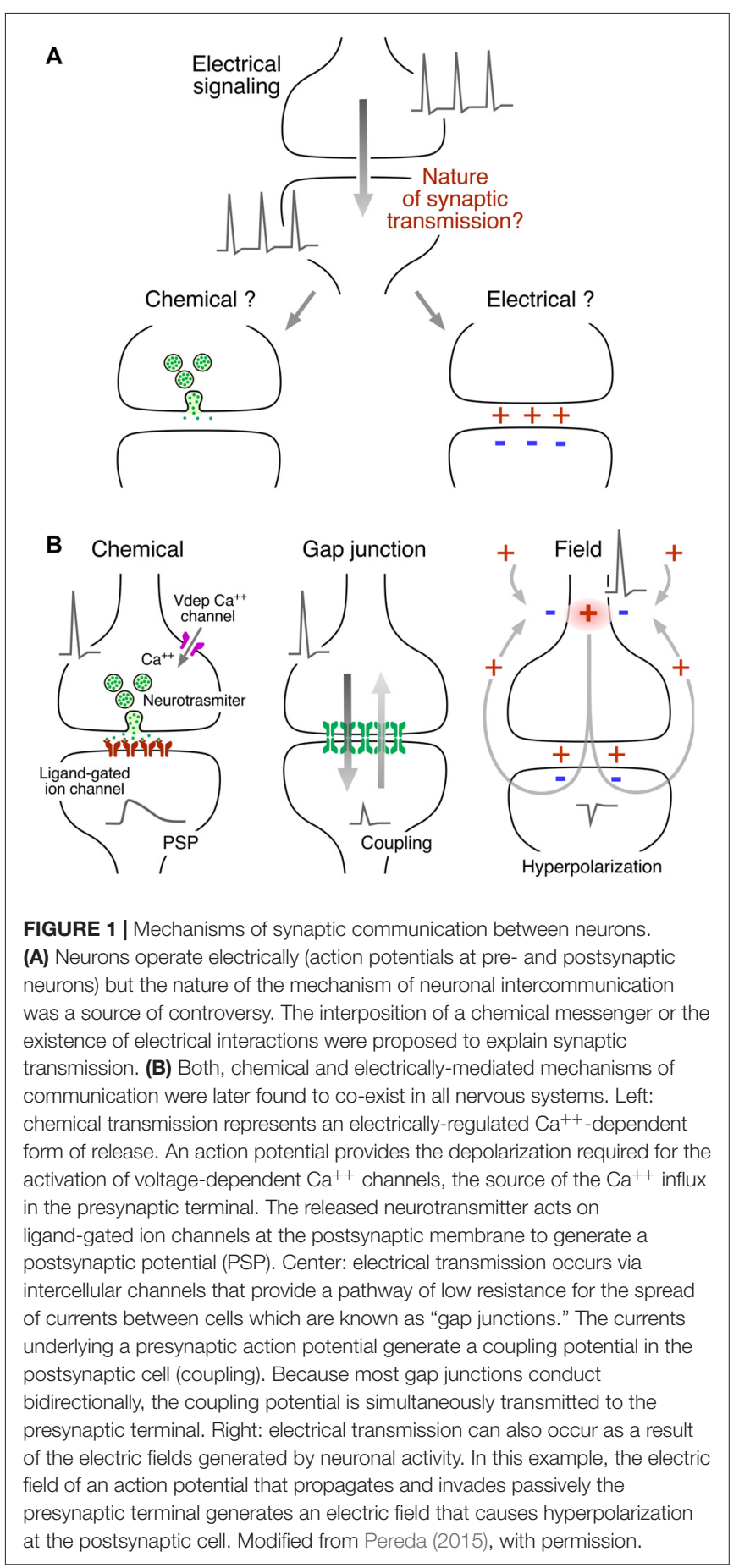

by nerve stimulation, leaving room to argue for electrical transmission.

Any model of electrical transmission must address a number of defining issues, including: (i) a mechanism for generating a postsynaptic signal strong enough to alter nerve cell excitability; (ii) a minimal synaptic delay, given the speed with which electricity travels in a conducting medium; and (iii) explaining how the same presynaptic signal, that is, an action potential, can produce excitation at some sites and 
inhibition at others. These three points are discussed separately below.

Fatt (1954) reviewed the two general mechanisms that could underlie electrical transmission. The first is a direct connection between the cytoplasms of the two coupled neurons via a low impedance path, with the degree of coupling being determined by the relative sizes of the coupling and "post-junctional" conductances. Although he considered this mode of transmission unlikely, coupling between nerve cells via gap junctions is now well-established, and these synapses can be uni- or bi-directional, depending on the voltage-dependent properties of the channel connexins (see below).

The second is "ephaptic" transmission or coupling via current flow through the extracellular space. This model dates back to experiments by Arvanitaki et al. (1964), who established artificial points of contact between two axons and showed current flow from one element to the next by applying an unbiologically powerful stimulus, the "detonator potential." While there are numerous examples where the electrical activity of populations of neurons is modulated or biased by local extracellular fields (reviewed by Weiss and Faber, 2010), evidence for field effects that have characteristics analogous to those of chemical synaptic transmission has only been demonstrated in a few model systems. Nevertheless, these effects can be quite powerful. The best known examples involve the Mauthner cell, an identified reticulospinal neuron that triggers an escape behavior in many teleosts, and cerebellar Purkinje cells. In the former, ephaptic inhibition mediated by a specific class of interneurons sets the startle response threshold, and in the latter, it controls Purkinje cell synchrony. According to the ephaptic model, current associated with a presynaptic action potential is "forced" across the postsynaptic membrane because there is a high extracellular impedance in the surrounding neuropil. Thus, ephaptic transmission meets the first requirement listed above, namely, sufficient strength to be physiologically relevant, due to a specialized extracellular structure which is postulated to contribute to a high extracellular resistance. These specializations are known as the axon cap of the Mauthner cell and the pericellular basket, or Pinceau, of Purkinje cells. In the case of speed, suffice it to note that in these well-studied systems there is no delay between the simultaneously recorded presynaptic action potential and the "postsynaptic" field effect. Finally, whether a field effect is excitatory or inhibitory depends upon the direction and magnitude of postsynaptic current flow at the excitable postsynaptic membrane region, as discussed below. Here, we focus on the type of field effect that is analogous to chemical transmission, with identified pre- and postsynaptic elements, and the modulatory effects mediated by synchronous activation of populations of neurons are reviewed elsewhere (Weiss and Faber, 2010).

Interestingly, Eccles, who was a major proponent of electrical transmission in the CNS until he provided, with Fatt (1954), the most compelling evidence for the chemical mode, proposed models for electrical excitation and inhibition in the $1940 \mathrm{~s}$ (Figure 2) which are still relevant today (Eccles, 1946; Brooks and Eccles, 1947). The models for electrical excitation and inhibition are quite straightforward; current from an extracellular source, e.g., the presynaptic axon, depolarizes and hyperpolarizes different regions of the postsynaptic membrane, with the constraints that: (i) the sum of imposed current flowing in across the neuronal membrane equals the sum of the outward current; and (ii) the functional sign of a field effect depends upon the direction of current flow across excitable postsynaptic membrane. The model proposed for electrical excitation postulated that a monophasic presynaptic
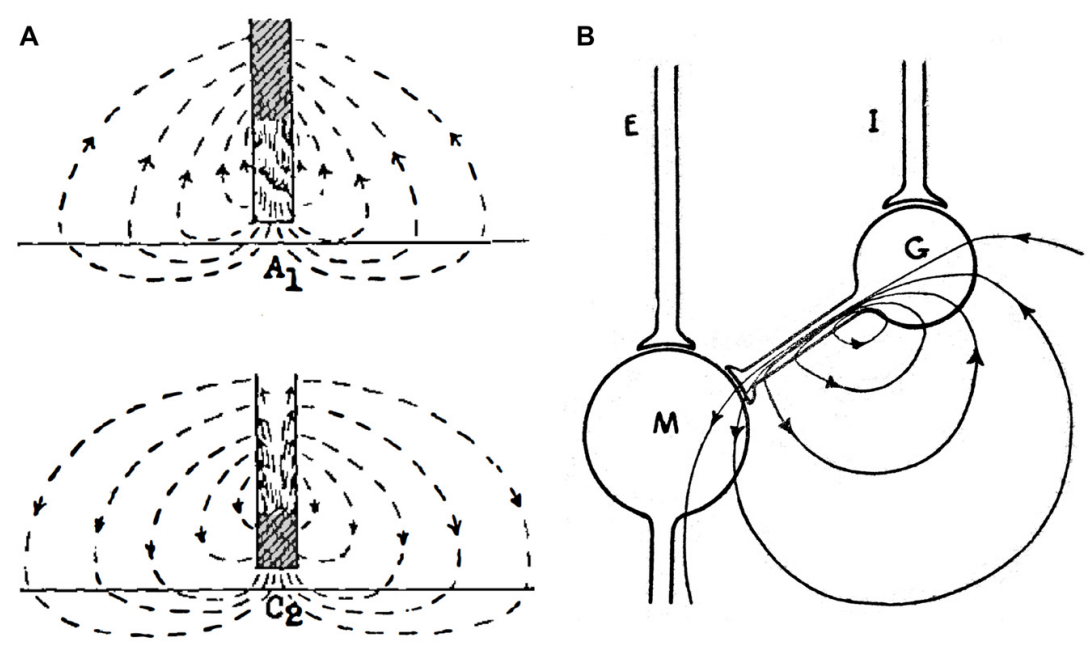

FIGURE 2 | Proposed mechanisms for electrical transmission. (A) The cartoon illustrates the hypothetical current flow generated by an action potential approaching a synaptic terminal (top) and at the synaptic terminal itself (bottom). The initial anodal effect (A1) is followed by a cathodal effect (C2) in the postsynaptic membrane directly facing the presynaptic terminal. (B) Early electrical theory of inhibition. Cartoon illustrates the current flow through the synaptic terminal of an interneuron (G) on a postsynaptic cell (M). To exert an inhibitory action, the interneuron should receive subthreshold stimulation by its afferent input (I). An excitatory input (E) into the postsynaptic cell is also represented. Reproduced from Eccles (1982), with permission. 
current entered inexcitable postsynaptic membrane apposed to the synaptic terminal and exited across adjacent excitable membrane, thereby depolarizing the latter (Figure 2A). For electrical inhibition, sign inversion was achieved by interjecting an inhibitory interneuron that is depolarized but not to threshold, with its current in turn hyperpolarizing the inexcitable region of the postsynaptic membrane (Figure 2B). Eccles recognized that the current would be excitatory elsewhere and suggested that the extensive neuronal dendritic tree served the function of dissipating the outward excitatory current across a large distributed area of membrane, thereby minimizing its effect on excitation. These models, with the addition of distinguishing effects of membrane capacitance and implications of presynaptic spike waveform, account for most features of ephaptic transmission.

Finally a set of elegant experiments by Katz, Fatt, Miledi and colleagues showed that chemical transmission is mediated by a $\mathrm{Ca}^{++}$-dependent electrically regulated form of release of neurotransmitter packets (Katz, 1969), which in turn are capable of generating an electrical signal in the postsynaptic cell by acting specifically on ligand-gated ion channels known as "receptors" (Figure 1B, left). It is now recognized that both modes of communication, electrical and chemical, are operative (Figure 1B).

\section{SYNAPTIC TRANSMISSION MEDIATED BY PATHWAYS OF LOW RESISTANCE: GAP JUNCTIONS}

As discussed above, Paul Fatt suggested that electrical currents generated in one neuron could directly spread to an adjacent postsynaptic cell via a pathway of low resistance. This idea led to the demonstration that, as postulated, presynaptic electrical currents can at some contacts propagate to the postsynaptic cell "electrotonically." Moreover, not only action potentials (as are most often required for chemical transmission) but also subthreshold signals were conducted to the postsynaptic cell. In other words, changes in the membrane potential in one cell were capable of spreading to a second cell, generating potentials of similar time course but smaller amplitude, as if the two cells were "electrically coupled." Electrotonic transmission was observed in both invertebrate (Watanabe, 1958; Furshpan and Potter, 1959) and vertebrate (Bennett et al., 1959; Furshpan, 1964) nervous systems.

Seminal experiments in fish (Robertson et al., 1963; Robertson, 1963; Furshpan, 1964; Pappas and Bennett, 1966; reviewed in Pereda and Bennett, 2017) led to the identification of the intercellular structure that serves as a pathway of low resistance for the spread of currents between neurons: the "gap junction." Convergent evidence for the role of these structures in mediating electrical coupling was obtained in the heart (reviewed in Delmar et al., 2004). Gap junctions are groupings of tightly clustered intercellular channels (Figure 3A) that allow diffusion of intracellular ions carrying electrical currents (Goodenough and Paul, 2009). The intercellular channel is formed by the docking of two apposed individual channels, named "hemichannels" or "connexons," one contributed by each of the coupled cells (Figure 3A). Hemichannels are hexamers made of connexins, a family of 21 genes in humans. Gap junctions are not exclusive to neurons, and they are present in virtually every tissue of an organism, acting as aqueous pores for metabolic support and chemical signaling

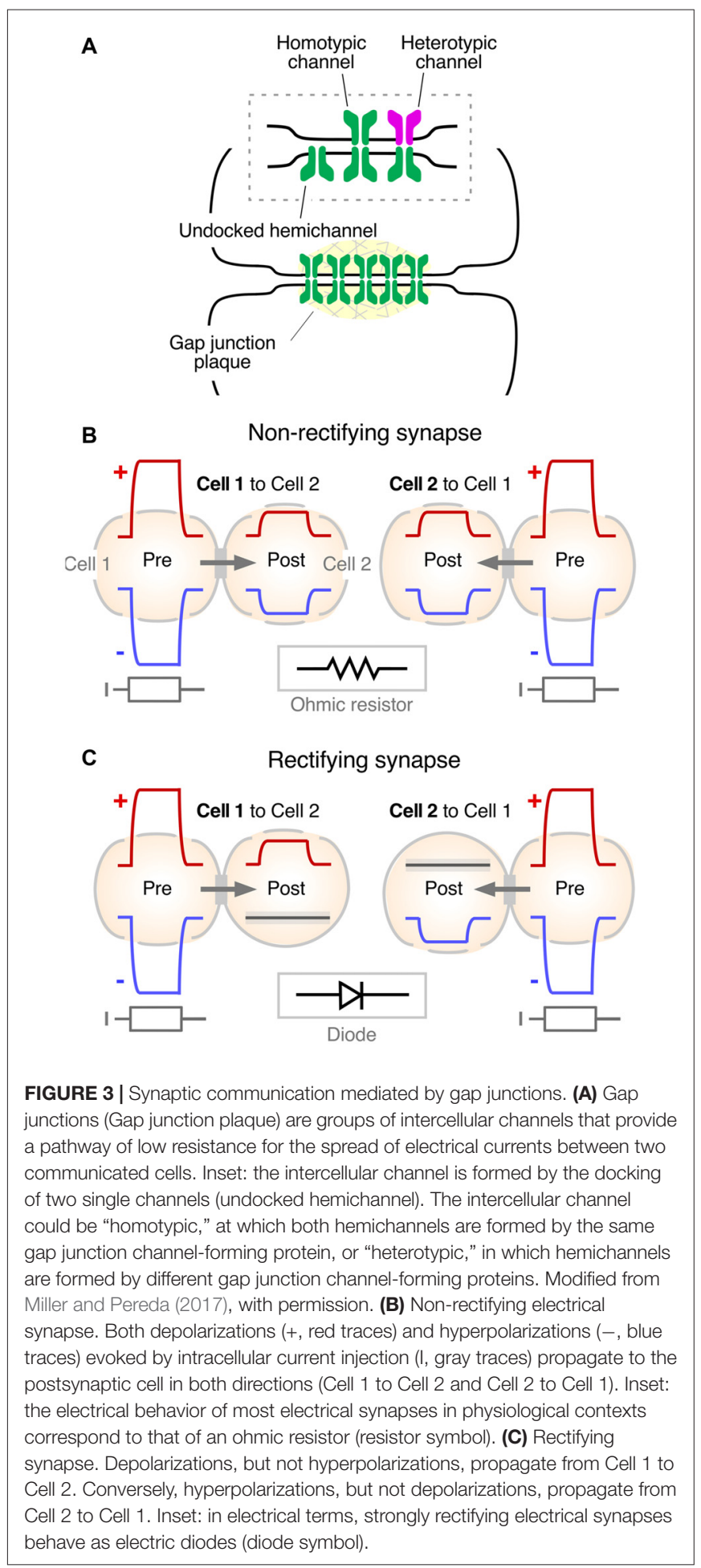


(Goodenough and Paul, 2009). Only a minority of the connexins (Cxs) are expressed in neurons: $\mathrm{Cx} 36, \mathrm{Cx} 45, \mathrm{Cx} 57, \mathrm{Cx} 30.2$ and Cx50 (Söhl et al., 2005; O’Brien, 2014; Miller and Pereda, 2017; Nagy et al., 2018). Amongst them, Cx36 (Condorelli et al., 1998) is considered the main gap junction protein supporting electrical transmission in vertebrates. Except for microglia (Dobrenis et al., 2005) and other cells of ectodermic origin such as pancreatic beta cells (Moreno et al., 2005) and chromaffin cells (Martin et al., 2001), its expression is restricted to neurons (Rash et al., 2000). Combined, its widespread distribution and neuronal preference make Cx36 and its vertebrate orthologs the main channel-forming protein of neuronal gap junctions. Interestingly, a similar clustered organization of intercellular channels was found at invertebrate gap junctions, where the channels are formed by a different protein named "innexin," a family of about 20 genes in C. elegans and 8 genes in the fly (Phelan et al., 1998; Phelan, 2005). Innexins form either hexameric or octameric hemichannels (Oshima et al., 2016; Skerrett and Williams, 2017). Remarkably, despite their unrelated sequences, connexins and innexins share a similar membrane topology and converge into similar structures with largely overlapping functions (Pereda and Macagno, 2017; Skerrett and Williams, 2017). There is a family of three genes found in vertebrates that share sequence similarities with innexins, the so-called "pannexins" (Panchin et al., 2000). Pannexins were found to be expressed in neurons (Bruzzone et al., 2003; Thompson et al., 2008), although there is no evidence so far indicating they form gap junctions in vivo and are capable of supporting electrical communication between neurons. Rather, they are thought to contribute functionally, operating as hemichannels (Dahl and Locovei, 2006; MacVicar and Thompson, 2010).

From the functional point of view, gap junction channels most commonly operate electrically as ohmic resistors, providing bidirectional communication for electrical signals between two or more cells (Figure 3B). Currents underlying action potentials in a presynaptic cell can directly flow via the gap junction to the postsynaptic cell, generating "electrical synaptic potentials" or "coupling potentials," which also are known as "spikelets" (Figure 1B, middle). Not only currents underlying action potentials but also those responsible for subthreshold signals such as synaptic potentials of either depolarizing or hyperpolarizing nature can spread to the postsynaptic cell to generate a coupling potential (Figure 3B). The strength or weight of the postsynaptic cell's response and the passive properties of the coupled cells are largely interdependent (Bennett, 1966; Getting, 1974). Accordingly, the amplitude of the coupling potential is determined not only by the conductance of the gap junction channels but also by the input resistance of the postsynaptic cell (see Bennett, 1966). In addition, the passive properties of the postsynaptic cell impose limitations to the transmission of presynaptic signals, depending on their duration. Short lasting signals such as action potentials are more attenuated than longer lasting signals such as synaptic potentials or afterhyperpolarizations due to the filtering properties of the postsynaptic membrane which are reflected by the membrane "time constant" of the cell (a parameter determined by the product of the cell's resistance and capacitance that expresses how rapidly the resting membrane potential of the cell can be modified by a given current). As a result, the "coupling coefficient," a measure of the synaptic strength, defined as the ratio between the amplitude of the postsynaptic coupling potential and that of the presynaptic signal, can be dramatically different for signals with different time courses.

Rather than simple conduits the gap junction channels themselves contribute to electrical communication. The molecular composition and properties of the gap junction intercellular channel have been shown to endow electrical transmission with voltage-dependent properties. Hemichannels that contribute to form the intercellular channel can be made of the same or different connexin or innexin proteins. Intercellular channels formed by hemichannels made of the same protein are called "homotypic," whereas channels formed by hemichannels made of different proteins are called "heterotypic" (Figure 3A, inset). Molecular differences between the involved hemichannels are commonly associated with rectification of electrical transmission (Barrio et al., 1991; Verselis et al., 1994) and, providing support for such prediction, this association has been observed for both connexin (Rash et al., 2013) and innexin-based electrical synapses (Phelan et al., 2008). Rectification refers to the ability of electrical currents to preferentially flow in one direction, in other words, they behave as electrical diodes. However, this property critically depends on the polarity of the signal. As observed in the crayfish giant fiber synapses (Furshpan and Potter, 1959; Giaume et al., 1987), depolarizations can travel from the presynaptic to the postsynaptic side but not in the opposite directions, and hyperpolarizations can travel from the postsynaptic to the presynaptic side but not the other direction (Figure 3C). The polarized features of electrical transmission suggest the existence of a voltage-sensitive mechanism underlying this property. Several mechanisms were proposed to contribute to steep electrical rectification of gap junction channels, such as that observed in crayfish. Electrical rectification can be a consequence of the separation of fixed positive and negative charges at opposite ends of heterotypic gap junction channels, configuring a "p-n junction," which results from asymmetries in the molecular composition of the hemichannels that form the intercellular channel (Oh et al., 1999). Alternatively, electrical rectification could result from the presence of charged cytosolic factors which alter channel conductance, such as $\mathrm{Mg}^{++}$(Palacios-Prado et al., 2013, 2014) and spermine (Musa et al., 2004), which were to shown to interact with the gap junction channel. Combinations of these or more factors are likely to contribute to this striking voltage-dependent feature of some electrical synapses (reviewed in Palacios-Prado et al., 2014). Finally, the conductance of neuronal gap junctions was shown to be target of numerous regulatory mechanisms that endow electrical synapses with plastic properties equivalent to those observed at chemical synapses (reviewed in Pereda et al., 2013; O’Brien, 2014, 2017; Pereda, 2014). 


\section{SYNAPTIC TRANSMISSION MEDIATED BY ELECTRIC FIELDS}

Theoretically, simple electrical circuits with biologically realistic constraints on the passive and active voltage-dependent properties of neurons, their spatial orientation and the conductivity of the extracellular space could be used to predict whether a single neuron or a group of synchronously active cells generate enough extracellular current to affect the excitability of neighboring cells. That small capacitive and ohmic currents do flow from one cell to the next is not in doubt (Figure 4). The question is whether the small fraction of the source current that will be channeled transcellularly is large enough to have functional significance? Weiss and Faber (2010) addressed that question by comparing the strengths of local field potentials (LFPs) associated with endogenous electrical activity of normal and epileptogenic hippocampal pyramidal neurons with the strengths of applied fields shown to modify the timing of spike activity, in vitro. The effective applied fields were weaker, consistent with the notion that fields effect rhythmogenesis and neuronal synchrony. This function is most likely exerted in homogeneous CNS structures where a population of neurons have similar morphologies and orientations, such that their currents sum, as for hippocampal and cortical pyramidal cells. Indeed, modeling combined with electrophysiological experiments suggest these modulations of ongoing activity may have functional significance (see, for example, Fröhlich and McCormick, 2010;
Anastassiou et al., 2011; Berzhanskaya et al., 2013; Han et al., 2018).

But, can this mechanism also underlie synaptic communication? Contrasting Eccles' models of ephaptic excitation and inhibition suggests that the former is relatively straightforward and is primarily a function of the parallel or radial alignment of a population of neighboring neurons and the conductivity of the extracellular space, i.e., of the relative impedance and the orientation of the transcellular and extracellular current pathways. Yet, there are no compelling examples of ephaptic excitation mediating a distinct synaptic function with identified pre- and postsynaptic elements. Indeed, it is surprising that the prominent examples of electrical interactions between neurons consistent with a synaptic function are inhibitory. They include the bidirectional inhibition between the teleost Mauthner cell and a class of inhibitory interneurons (Faber and Korn, 1973; Korn and Faber, 1976; Korn et al., 1978), and the connection between cerebellar Basket cells and Purkinje cells (Korn and Axelrad, 1980; Blot and Barbour, 2014). Furthermore, these model systems share structural specializations and physiological properties, lending support to the hypothesis that these examples represent a form of electrical synaptic action.

The Mauthner cell is a large identifiable midbrain neuron found in many teleosts, and it has a number of morphological specializations that make it an unique model system. Furukawa and Furshpan (1963) discovered the first example of electrical
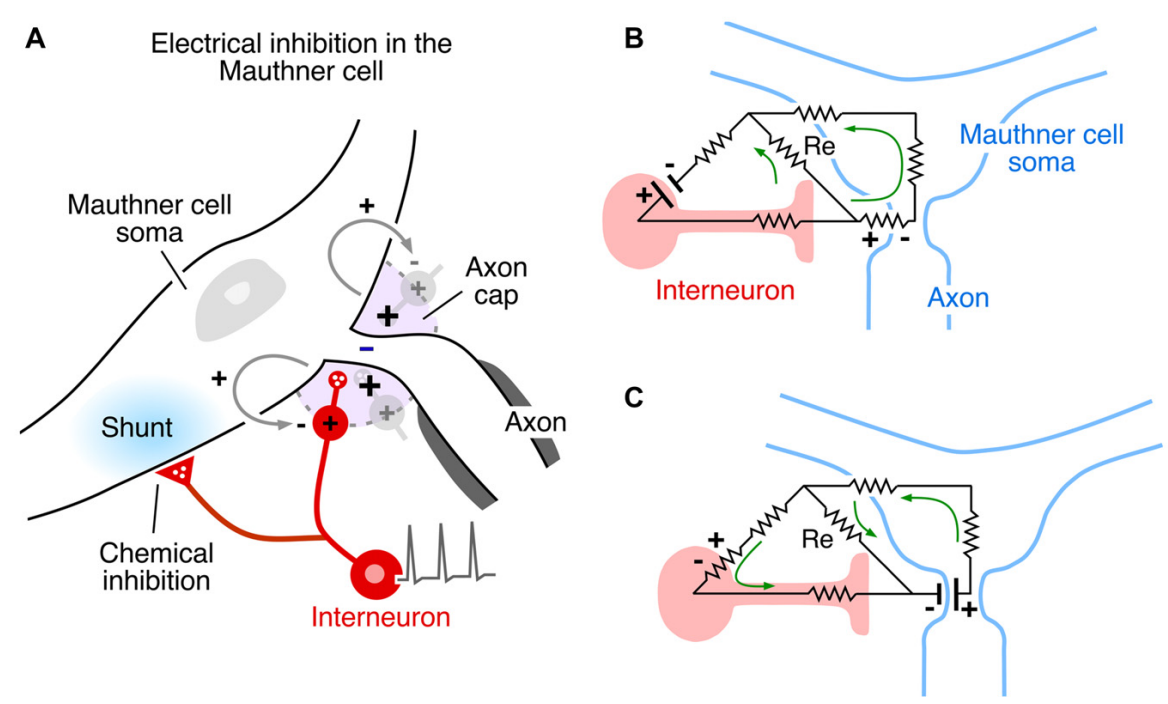

FIGURE 4 | Inhibitory synaptic action in the Mauthner cell network mediated by electric fields. (A) Mixed electrical and chemical inhibition of the Mauthner cell mediated by action potentials in axonal endings of identified inhibitory interneurons (red). Some axon branches converge on the Mauthner cell's Axon cap (violet) around its initial segment, and their action currents generate a hyperpolarizing extracellular positivity in the cap. The interneuron's axons within and outside the cap are glycinergic and mediate chemical inhibition of the Mauthner cell, manifest as a postsynaptic shunt (blue regions). Modified from Pereda and Faber (2011), with permission. (B,C) Resistive circuit models demonstrating current flow associated with electrical inhibition of the Mauthner cell (B), and of the inhibitory interneuron. (C) When the interneuron is activated, its action current is channeled through the axon and in across the Mauthner axon's initial segment, generating an extracellular positivity in the axon cap, thereby hyperpolarizing the axon. When the Mauthner axon's initial segment is activated, its action current is directed inward across the interneuron's excitable membrane and returns to the source through the inexcitable terminal axon. Panels (B,C) modified from Faber and Korn (1989), with permission. 
inhibition when comparing the intra- and extracellular potentials evoked in the axon cap by antidromic stimulation of this neuron's axon-as noted, the axon cap is a dense neuropil surrounding the initial segment of the Mauthner cell axon. First, the antidromic action potential in the extracellular space $(\mathrm{Ve})$ is very large and negative, as much as $-40 \mathrm{mV}$, and the corresponding spike height recorded intra-axonally ( $\mathrm{Vi}$ ) at the site of spike initiation is smaller, $\sim+50 \mathrm{mV}$, so that the full transmembrane spike height, calculated as the difference between the intra- and extracellular responses, i.e., Vi - Ve, +90 mv (Furshpan and Furukawa, 1962). This observation of such a large extracellular potential associated with one neuron's action potential suggested a high resistance barrier to extracellular current, and it has been proposed that this property is a consequence of the structure of the axon cap: swelling of interneuron axons at the edge of the cap, and close proximity to a densely packed ring of glia at the same boundary, known as the "canestro" or "basket" of Beccari (1907). These morphological features represent cellular specializations that support electrical communication and, therefore, may be analogous to structural specializations found at chemical synapses. Furthermore, the antidromic spike was succeeded by an extracellular positivity, which they named the Extrinsic Hyperpolarizing Potential (EHP) since it was larger than its intracellular representation, and, thus the same calculation showed that $(\mathrm{Vi}-\mathrm{Ve})<0$ and that the EHP is inhibitory. It was shown subsequently that the EHP was generated by impulses in a class of inhibitory interneurons that mediate feedback and feedforward inhibition of the Mauthner cell and that the evoked inhibition has two components, with a classical glycinergic inhibition of the Mauthner cell following the electrical component by $\sim 0.5 \mathrm{~ms}$ (Figure $4 \mathbf{A}$; Korn and Faber, 1976). In the case of the feedforward circuit, the short latency allows electrical inhibition to occur synchronously with excitation, thereby limiting the duration of the decisionmaking window in processing information by the Mauthner cell. Thus, these connections mediate mixed, electrical and chemical, synaptic actions (Figure $\mathbf{4 A}$ ).

Additional specializations support the notion that electrical inhibition is physiological and functionally relevant. For example, the presynaptic spike in the inhibitory interneurons propagates passively within the cap, where the afferent axon loses its myelination. Consequently, the local field is monophasic, increasing its effectiveness. The EHP, which acts as an extracellular anode, that is, as an external current source, can be as large as $20 \mathrm{mV}$. Paired pre- and postsynaptic recordings show that the contribution of a single interneuron is about $0.4 \mathrm{mV}$ per presynaptic spike, suggesting about 50 interneurons discharge synchronously following antidromic stimulation This is a powerful population effect that shuts down the Mauthner cell for 10's of milliseconds. However, as noted above, these neurons are also excited in a feedforward circuit that relays auditory information to the Mauthner cell. In this case the EHP is graded as a function of stimulus strength, and it serves to set the threshold of a sound-evoked behavior, the escape response: when a sound-evoked EHP is canceled by an applied cathodal current in the axon cap, the underlying subthreshold EPSP is converted to suprathreshold, triggering Mauthner cell activation (Weiss et al., 2008).

Other factors which influence the operation of electrical inhibition include the orientation of the involved neurons and the distribution of excitable membrane relative to extracellular current sources and sinks. The Mauthner cell system is an ideal model for extracting mechanistic features, especially since there is reciprocal inhibition in the network, that is, the interneurons are inhibited by the Mauthner cell action currents (electric currents that originate from variations of potential during neural activity). Figures 4B,C contrasts the two examples. In both cases, the inhibitory current is channeled inward across excitable membrane, namely the Mauthner axon initial segment (Figure 4B) or the last node, or heminode, of the inhibitory interneuron's axon (Figure 4C). Conversely, it exits the target through inexcitable membrane, that is, across soma-dendritic- or axon terminal membrane, respectively. Thus, if the distribution of excitable or inexcitable membrane were altered, the sign and magnitude of the ephaptic action would be altered accordingly. These considerations pertain to other networks as well, as discussed below.

Since the consequences of different spatial and functional arrangements are not necessarily intuitive, Figure 5 illustrates different combinations. In Figure 5A an inward postsynaptic current is inhibitory if the postsynaptic membrane is inexcitable at the site of contact, and it can be excitatory if the obligatory outward current exits through excitable membrane. The two examples in Figure 5B contrast the inhibitory and excitatory field effects generated at axo-axonic and axo-somatic contacts, respectively, when the excitable membrane is restricted to the axonal initial segment. It should be noted that these general examples do not factor in the dependence of the strength of the corresponding electrical interaction on the density and spatial distribution of current flow.

It is noteworthy that another system with well-studied ephaptic inhibition is the cerebellar pinceau where terminal axons of basket cells form a densely packed sheath around the Purkinje cell initial axon segment. This unusual axonic arrangement of inhibitory basket cells on Purkinje cells can be also considered, as in the Mauthner cell, a synaptic specialization supporting electrical transmission. Blot and Barbour (2014) showed that this ephaptic inhibition could, at very weak fields produced by a spike in a single basket cell, reduce the firing rate of an active Purkinje cell. They postulated that the coupling between cells was due to capacitive current flow, not to resistive current as suggested for the Mauthner cell. However, the time constants of the Mauthner cell and of the inhibitory interneurons are unusually brief, in the range of 100-200 microseconds, and 2 milliseconds, respectively, suggesting resistive coupling is a major portion of the electrical inhibition in that network. Regardless, the speed of coupling in both systems may be one function of electrical inhibitory synapses.

Evidence is slowly accumulating that ephaptic currents generated by single neurons can be detected, and they have been shown to influence neuronal firing patterns in diverse structures, including teleost midbrain (2005), mammalian cortex (Anastassiou et al., 2011), cerebellar cortex 


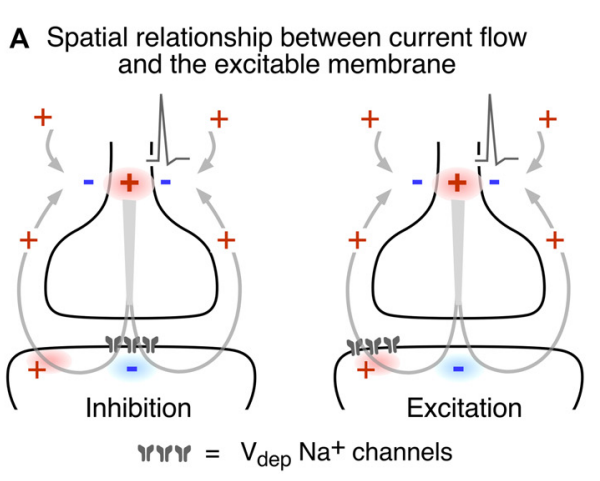

B

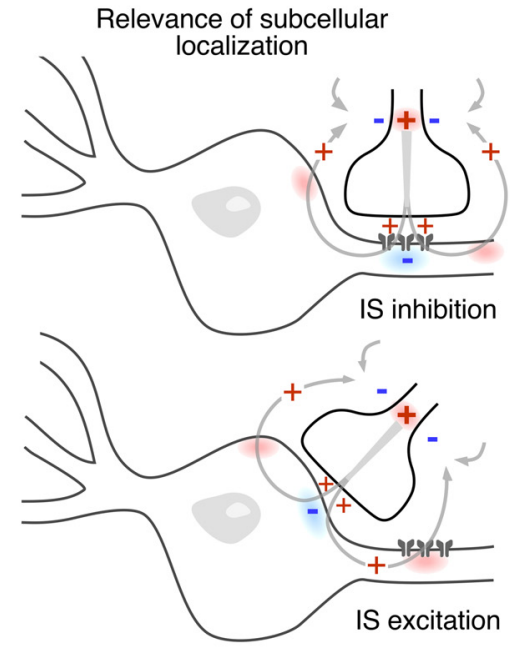

FIGURE 5 | Presynaptic electric fields can exert both excitatory and inhibitory actions on a postsynaptic cell. (A) Whether an ephaptic current is excitatory or inhibitory depends on both the direction of current flow and the properties of postsynaptic membrane. The schematic model contact establishes the same currents in both examples, but excitable postsynaptic membrane, depicted as a cluster of voltage-dependent $\mathrm{Na}^{+}$channels, is either restricted to the contact zone, in the case of electrical inhibition, or is displaced laterally, for electrical excitation. (B) The subcellular localization of presynaptic contacts also influences the polarity of an ephaptic synapse. Upper and lower schemes contrast axo-axonic and axo-somatic "electrical" synapses, respectively. The former is inhibitory because an inward hyperpolarizing current is imposed upon excitable postsynaptic membrane while the latter is instead excitatory because the current across the postsynaptic excitable membrane is outward.

(Blot and Barbour, 2014) and snail CNS (Bravarenko et al., 2005). These findings suggest that physiologically relevant ephaptic interactions may be more ubiquitous than appreciated, a prospect supported by formal models of ordered structures, such as olfactory nerve (Bokil et al., 2001) and other olfactory structures (Van der Goes van Naters, 2013) and retina (Byzov and Shura-Bura, 1986; Vroman et al., 2013) but see (Kramer and Davenport, 2015), subject to structural and biophysical constraints, including the properties discussed here.

\section{SUMMARY}

The nervous system relies on electrical signaling to perform the fast computations that underlie animal behavior. Not surprisingly, intercellular communication between neurons can be mediated not only by the action of chemical transmitters, but also by electrical signaling. In turn, electrical communication occurs via two main mechanisms: one involves pathways of low resistance between neighboring neurons that are provided by intercellular channels (gap junctions), while the second, which is generally less appreciated, occurs as a consequence of the extracellular electrical fields generated by neurons during electrical signaling. Electrical signals generated by one cell can thus modify the excitability of its neighbors via one, or both, of these mechanisms. As with chemical transmission, each of the two modes of electrical transmission depends upon distinctive structural specializations, namely gap junctions in one case and a dense high resistance neuropil in the other.

Ephaptic interactions are generally perceived as only occurring in a diffuse manner, particularly in situations where the activity of a group of neurons influences the excitability of its neighbors. These interactions were proposed to play physiological (LFPs) and pathological roles (seizure maintenance). On the other hand, there are examples where presynaptic cellular specializations are found in close proximity to specific regions of the postsynaptic cell. This is the case for the axon terminals of inhibitory interneurons which impinge on the Mauthner cell, within the axon cap, and on cerebellar Purkinje cells, in the basket cell pinceau: in both cases these endings are located in close proximity to the initial segment of the "postsynaptic" cell. From our perspective, these two examples qualify as synapses, as presynaptic specializations enable localized actions on a very specific region of the postsynaptic cell. In addition to presynaptic anatomical specializations the interactions require an unusual high resistivity (or impedance) of the extracellular space. Moreover, these specializations were shown to be functionally and behaviorally relevant. More than one set of structural and physiological conditions are consistent with the electric field modality of synaptic communication. That is, the required anatomical and functional specializations do not follow a general pattern and seem specific for each case, making the identification of new examples by anatomical means particularly challenging. However, the Mauthner cell axon cap and the basket cell pinceau on the Purkinje cell unambiguously represent synaptic specializations and constitute the focus of this review article.

Despite the predominance of electrical signaling in the nervous system, synaptic communication ubiquitously occurs via the interposition of a chemical messenger, or neurotransmitter, between synaptically-connected cells. Chemical communication is likely an evolutionarily earlier communication strategy, as it occurs between unicellular organisms ( $\mathrm{Li}$ and Nair, 2012). However, chemical communication between neurons is controlled by and capable of generating electrical signals: evoked transmitter release requires presynaptic depolarization and neurotransmitter receptors generate postsynaptic electrical signals (Sheng et al., 2012). Given such a close interrelationship between electrical signaling and chemical communication, the latter was also called "electrochemical transmission" (Llinás, 2001). 
Despite their dependence on electricity, these three forms of communication co-exist because their individual properties differentially contribute to the processing of information within circuits. Chemical synapses, in addition to having receptors that gate ligand-bound ion channels capable of generating changes in the membrane potential of the cell following activation, have metabotropic receptors capable of activating a variety of biochemical cascades. Activation of biochemical cascades can occur following the binding of neurotransmitter to either ionotropic and metabotropic receptors and could lead to long-term modification of synaptic and/or cellular properties and induction of gene expression (Sheng et al., 2012). Thus, chemical synapses have the ability to transform a presynaptic signal into a variety of spatial and temporal patterns, an adaptive property that contributes to a great extent to the diversity of synaptic communication in the brain.

In contrast, the lack of a measurable synaptic delay implies that electrical transmission may be better adapted to ensure fast processing of signals through neural networks. While the two forms of electrical transmission have in common a high-speed of synaptic communication they however seem to serve different roles in communication, from the network point of view. There are, so far, fewer examples of electrical communication mediated by electric fields and as a result, less is known of the underlying mechanism. It is, however, known that its actions are localized on critical subcellular locations, such as the neuron's initial segment. This feature allows synapses mediated by electric fields to convey exquisite timing information to decision-making cells within a circuit. Because of its speed, electrical transmission mediated by fields was shown to be critical in the processing of auditory information

\section{REFERENCES}

Anastassiou, C. A., Perin, R., Markram, H., and Koch, C. (2011). Ephaptic coupling of cortical neurons. Nat. Neurosci. 14, 217-223. doi: 10.1038/nn.2727

Armstrong, C. M. (2007). Life among the axons. Annu. Rev. Physiol. 69, 1-18. doi: 10.1146/annurev.physiol.69.120205.124448

Arvanitaki, A., Chalozonitis, N., and Costa, H. (1964). Excitation of the giant neuron by crossed exponential transmembranal currents (aplysia fasciata). C. R. Seances Soc. Biol. Fil. 158, 2373-2377.

Barrio, L. C., Suchyna, T., Bargiello, T., Xu, L. X., Roginski, R. S., Bennett, M. V., et al (1991). Gap junctions formed by connexins 26 and 32 alone and in combination are differently affected by applied voltage. Proc. Natl. Acad. Sci. U S A 88, 8410-8414. doi: 10.1073/pnas.88.19.8410

Beccari, N. (1907). Richerche sulle cellule e fibre del mauthner e sulle conessioni in pesci es anfibii. Asrch. Ital. Anat. Embriol. 6, 660-705.

Bennett, M. V. (1966). Physiology of electrotonic junctions. Ann. N Y Acad. Sci. 137, 509-539. doi: 10.1111/j.1749-6632.1966.tb50178.x

Bennett, M. V., Crain, S. M., and Grundfest, H. (1959). Electrophysiology of supramedullary neurons in spheroides maculatus. III. organization of the supramedullary neurons. J. Gen. Physiol. 43, 221-250. doi: 10.1085/jgp.43. 1.221

Berzhanskaya, J., Chernyy, N., Gluckman, B. J., Schiff, S. J., and Ascoli, G. A. (2013). Modulation of hippocampal rhythms by subthreshold electric fields and network topology. J. Comput. Neurosci. 34, 369-389. doi: 10.1007/s10827-0120426-4

Blot, A., and Barbour, B. (2014). Ultra-rapid axon-axon ephaptic inhibition of cerebellar purkinje cells by the pinceau. Nat. Neurosci. 17, 289-295. doi: $10.1038 / \mathrm{nn} .3624$ by the circuits that control the excitability of the teleost Mauthner cell (Weiss et al., 2008), and this mechanism is likely to play similar roles in controlling the activation of Purkinje neurons by cerebellar circuits (Blot and Barbour, 2014). In contrast, electrical synapses mediated by gap junctions are more widely distributed within neural networks and, a result of their bidirectionality, promote coordinated network activity by allowing computation of subthreshold variations of membrane potential between electrically-coupled cells. While promoting electrical synchronization is the signature property of gap junction mediated electrical synapses, their functional roles also include desynchronization, enhancement of signal to noise ratio, and coincidence detection, amongst others (reviewed in Connors, 2017).

Finally, the functional value of each form of transmission has its unique valence, which cannot be accomplished by the other. This functional categorization, is emphasized by the existence of mixed transmission at synaptic contacts at which chemical and electrical transmission, mediated by either gap junctions (Furshpan, 1964) or electric fields (Korn and Faber, 1976), act in concert to secure communication with a postsynaptic cell.

\section{AUTHOR CONTRIBUTIONS}

Both authors wrote the article.

\section{FUNDING}

This research was supported by National Institutes of Health grants DC03186, DC011099, NS055726, NS085772 and NS0552827 to AP.

Bokil, H., Laaris, N., Blinder, K., Ennis, M., and Keller, A. (2001). Ephaptic interactions in the mammalian olfactory system. J. Neurosci. 21:RC173. doi: 10.1523/jneurosci.21-20-j0004.2001

Bravarenko, N. I., Malyshev, A. Y., Voronin, L. L., and Balaban, P. M. (2005). Ephaptic feedback in identified synapses in mollusk neurons. Neurosci. Behav. Physiol. 35, 781-787. doi: 10.1007/s11055-005-0124-z

Brooks, C. M., and Eccles, J. C. (1947). An electrical hypothesis of central inhibition. Nature 159, 760-764. doi: 10.1038/159760a0

Bruzzone, R., Hormuzdi, S. G., Barbe, M. T., Herb, A., and Monyer, H. (2003). Pannexins, a family of gap junction proteins expressed in brain. Proc. Natl. Acad. Sci. U S A 100, 13644-13649. doi: 10.1073/pnas.22334 64100

Byzov, A. L., and Shura-Bura, T. M. (1986). Electrical feedback mechanism in the processing of signals in the outer plexiform layer of the retina. Vision Res. 26, 33-44. doi: 10.1016/0042-6989(86)90069-6

Condorelli, D. F., Parenti, R., Spinella, F., Trovato Salinaro, A., Belluardo, N., Cardile, V., et al. (1998). Cloning of a new gap junction gene (Cx36) highly expressed in mammalian brain neurons. Eur. J. Neurosci. 10, 1202-1208. doi: 10.1046/j.1460-9568.1998.00163.x

Connors, B. W. (2017). Synchrony and so much more: diverse roles for electrical synapses in neural circuits. Dev. Neurobiol. 77, 610-624. doi: 10.1002/dneu. 22493

Dahl, G., and Locovei, S. (2006). Pannexin: to gap or not to gap, is that a question? IUBMB Life 58, 409-419. doi: 10.1080/15216540600794526

Delmar, M., Duffy, H. S., Sorgen, P. L., Taffet, S. M., and Spray, D. C. (2004). "Molecular organization and regulation of the cardiac gap junction channel connexin43," in Cardiac Electrophysiol, eds D. P. Zipes and J. Jalife (Philadelphia: W.B. Saunders), 66-76. 
Dobrenis, K., Chang, H.-Y., Pina-Benabou, M. H., Woodroffe, A., Lee, S. C., Rozental, R., et al. (2005). Human and mouse microglia express connexin36 and functional gap junctions are formed between rodent microglia and neurons. J. Neurosci. Res. 82, 306-315. doi: 10.1002/jnr. 20650

Eccles, J. C. (1946). Synaptic potentials of motoneurons. J. Neurophysiol. 9, 87-120. doi: $10.1152 /$ jn.1946.9.2.87

Eccles, J. C. (1961). The mechanism of synaptic transmission. Ergeb. Physiol. 51, 299-430. doi: 10.1007/978-3-642-49946-3_8

Eccles, J. C. (1982). The synapse: from electrical to chemical transmission. Annu. Rev. Neurosci. 5, 325-339. doi: 10.1146/annurev.ne.05.030182.001545

Faber, D. S., and Korn, H. (1973). A neuronal inhibition mediated electrically. Science 179, 577-578. doi: 10.1126/science.179.4073.577

Faber, D. S., and Korn, H. (1989). Electrical field effects: their relevance in central neural networks. Physiol. Rev. 69, 821-863. doi: 10.1152/physrev.1989.69. 3.821

Fatt, P. (1954). Biophysics of junctional transmission. Physiol. Rev. 34, 674-710. doi: 10.1152/physrev.1954.34.4.674

Finger, S. (2005). Minds Behind the Brain. USA: Oxford University Press.

Franklin, B. (1751). Experiments and Observations on Electricity Made at Philadelphia in America. Printed and sold by E. Cave, at St. John's Gate. doi: 10.5479/sil.211644.39088000092304.

Fröhlich, F., and McCormick, D. A. (2010). Endogenous electric fields may guide neocortical network activity. Neuron 67, 129-143. doi: 10.1016/j.neuron.2010. 06.005

Furshpan, E. J. (1964). "Electrical transmission" at an excitatory synapse in a vertebrate brain. Science 144, 878-880. doi: 10.1126/science.144.3620.878

Furshpan, E. J., and Furukawa, T. (1962). Intracellular and extracellular responses of the several regions of the mauthner cell of the goldfish. J. Neurophysiol. 25, 732-771. doi: 10.1152/jn.1962.25.6.732

Furshpan, E. J., and Potter, D. D. (1959). Transmission at the giant motor synapses of the crayfish. J. Physiol. 145, 289-325. doi: 10.1113/jphysiol.1959. sp006143

Furukawa, T., and Furshpan, E. J. (1963). Two inhibitory mechanisms in the mauthner neurons of goldfish. J. Neurophysiol. 26, 140-176. doi: 10.1152/jn. 1963.26.1.140

Galvani, L. (1791). Aloysii Galvani De viribus electricitatis in motu musculari commentarius. Bononiae: Ex Typographia Instituti Scientiarum, 1791. doi: 10.5479/sil.324681.39088000932442.

Getting, P. A. (1974). Modification of neuron properties by electrotonic synapses. I. input resistance, time constant and integration. J. Neurophysiol. 37, 846-857. doi: 10.1152/jn.1974.37.5.846

Giaume, C., Kado, R. T., and Korn, H. (1987). Voltage-clamp analysis of a crayfish rectifying synapse. J. Physiol. 386, 91-112. doi: 10.1113/jphysiol.1987.sp0 16524

Goodenough, D. A., and Paul, D. L. (2009). Gap junctions. Cold Spring Harb. Perspect. Biol. 1:a002576. doi: 10.1101/cshperspect.a002576

Han, K.-S., Guo, C., Chen, C. H., Witter, L., Osorno, T., and Regehr, W. G. (2018). Ephaptic coupling promotes synchronous firing of cerebellar purkinje cells. Neuron 100, 564.e3-578.e3. doi: 10.1016/j.neuron.2018.09.018

Hodgkin, A. L., and Huxley, A. F. (1952). Currents carried by sodium and potassium ions through the membrane of the giant axon of loligo. J. Physiol. 116, 449-472. doi: 10.1113/jphysiol.1952.sp004717

Katz, B. (1969). "The release of neural transmitter substances," in Sherrington Lecture, (Liverpool: Liverpool University Press).

Korn, H., and Axelrad, H. (1980). Electrical inhibition of purkinje cells in the cerebellum of the rat. Proc. Natl. Acad. Sci. U S A 77, 6244-6247. doi: 10.1073/pnas.77.10.6244

Korn, H., and Faber, D. S. (1976). Vertebrate central nervous system: same neurons mediate both electrical and chemical inhibitions. Science 194, 1166-1169. doi: $10.1126 /$ science. 186868

Korn, H., Triller, A., and Faber, D. S. (1978). Structural correlates of recurrent collateral interneurons producing both electrical and chemical inhibitions of the mauthner cell. Proc. R. Soc. London. Ser. B Biol. Sci. 202, 533-538. doi: $10.1098 / \mathrm{rspb} .1978 .0085$

Kramer, R. H., and Davenport, C. M. (2015). Lateral inhibition in the vertebrate retina: the case of the missing neurotransmitter. PLoS Biol. 13:e1002322. doi: 10.1371/journal.pbio.1002322
Li, Z., and Nair, S. K. (2012). Quorum sensing: how bacteria can coordinate activity and synchronize their response to external signals? Protein Sci. 21, 1403-1417. doi: $10.1002 /$ pro. 2132

Llinás, R. (2001). I of the Vortex: from Neurons to Self. Cambridge: MIT Press.

MacVicar, B. A., and Thompson, R. J. (2010). Non-junction functions of pannexin-1 channels. Trends Neurosci. 33, 93-102. doi: 10.1016/j.tins.2009. 11.007

Martin, A. O., Mathieu, M. N., Chevillard, C., and Guérineau, N. C. (2001). Gap junctions mediate electrical signaling and ensuing cytosolic $\mathrm{Ca}^{2+}$ increases between chromaffin cells in adrenal slices: a role in catecholamine release. J. Neurosci. 21, 5397-5405. doi: 10.1523/jneurosci.21-15-05397.2001

Miller, A. C., and Pereda, A. E. (2017). The electrical synapse: molecular complexities at the gap and beyond. Dev. Neurobiol. 77, 562-574. doi: 10.1002/dneu.22484

Moreno, A. P., Berthoud, V. M., Pérez-Palacios, G., and Pérez-Armendariz, E. M. (2005). Biophysical evidence that connexin-36 forms functional gap junction channels between pancreatic mouse $\beta$-cells. Am. J. Physiol. Endocrinol. Metab. 288, E948-E956. doi: 10.1152/ajpendo.00216.2004

Musa, H., Fenn, E., Crye, M., Gemel, J., Beyer, E. C., and Veenstra, R. D. (2004). Amino terminal glutamate residues confer spermine sensitivity and affect voltage gating and channel conductance of rat connexin 40 gap junctions. J. Physiol. 557, 863-878. doi: 10.1113/jphysiol.2003.059386

Nagy, J. I., Pereda, A. E., and Rash, J. E. (2018). Electrical synapses in mammalian CNS: past eras, present focus and future directions. Biochim. Biophys. Acta Biomembr. 1860, 102-123. doi: 10.1016/j.bbamem.2017.05.019

O’Brien, J. (2014). The ever-changing electrical synapse. Curr. Opin. Neurobiol. 29, 64-72. doi: 10.1016/j.conb.2014.05.011

O’Brien, J. (2017). Design principles of electrical synaptic plasticity. Neurosci. Lett. doi: 10.1016/j.neulet.2017.09.003 [Epub ahead of print].

Oh, S., Rubin, J. B., Bennett, M. V., Verselis, V. K., and Bargiello, T. A. (1999). Molecular determinants of electrical rectification of single channel conductance in gap junctions formed by connexins 26 and 32. J. Gen. Physiol. 114, 339-364. doi: 10.1085/jgp.114.3.339

Oshima, A., Tani, K., and Fujiyoshi, Y. (2016). Atomic structure of the innexin-6 gap junction channel determined by cryo-EM. Nat. Commun. 7:13681. doi: $10.1038 /$ ncomms 13681

Palacios-Prado, N., Hoge, G., Marandykina, A., Rimkute, L., Chapuis, S., Paulauskas, N., et al. (2013). Intracellular magnesium-dependent modulation of gap junction channels formed by neuronal connexin36. J. Neurosci. 33, 4741-4753. doi: 10.1523/jneurosci.2825-12.2013

Palacios-Prado, N., Huetteroth, W., and Pereda, A. E. (2014). Hemichannel composition and electrical synaptic transmission: molecular diversity and its implications for electrical rectification. Front. Cell. Neurosci. 8:324. doi: $10.3389 /$ fncel.2014.00324

Panchin, Y., Kelmanson, I., Matz, M., Lukyanov, K., Usman, N., and Lukyanov, S. (2000). A ubiquitous family of putative gap junction molecules. Curr. Biol. 10, R473-R474. doi: 10.1016/s0960-9822(00)00576-5

Pappas, G. D., and Bennett, M. V. (1966). Specialized junctions involved in electrical transmission between neurons. Ann. N Y Acad. Sci. 137, 495-508. doi: 10.1111/j.1749-6632.1966.tb50177.x

Pereda, A. E. (2014). Electrical synapses and their functional interactions with chemical synapses. Nat. Rev. Neurosci. 15, 250-263. doi: 10.1038/nrn3708

Pereda, A. E. (2015). Neurobiology: all synapses are created equal. Curr. Biol. 25, R38-R41. doi: 10.1016/j.cub.2014.11.029

Pereda, A. E., and Bennett, M. V. L. (2017). "Electrical synapses in fish: relevance to synaptic transmission," in Electrical Coupling and Microcircuits: Network Functions and Plasticity, ed. J. Jing (London, UK: Academic Press), 1-18.

Pereda, A. E., Curti, S., Hoge, G., Cachope, R., Flores, C. E., and Rash, J. E. (2013). Gap junction-mediated electrical transmission: regulatory mechanisms and plasticity. Biochim. Biophys. Acta 1828, 134-146. doi: 10.1016/j.bbamem. 2012.05.026

Pereda, A. E., and Faber, D. S. (2011). Physiology of the Mauthner Cell: Discovery and Properties. Amsterdam: Elsevier Inc.

Pereda, A. E., and Macagno, E. (2017). Electrical transmission: two structures, same functions? Dev. Neurobiol. 77, 517-521. doi: 10.1002/dneu.22488

Phelan, P. (2005). Innexins: members of an evolutionarily conserved family of gap-junction proteins. Biochim. Biophys. Acta 1711, 225-245. doi: 10.1016/j. bbamem.2004.10.004 
Phelan, P., Goulding, L. A., Tam, J. L., Allen, M. J., Dawber, R. J., Davies, J. A., et al. (2008). Molecular mechanism of rectification at identified electrical synapses in the drosophila giant fiber system. Curr. Biol. 18, 1955-1960. doi: 10.1016/j.cub. 2008.10.067

Phelan, P., Stebbings, L. A., Baines, R. A., Bacon, J. P., Davies, J. A., and Ford, C. (1998). Drosophila shaking-B protein forms gap junctions in paired xenopus oocytes. Nature 391, 181-184. doi: 10.1038/34426

Piccolino, M. (1998). Animal electricity and the birth of electrophysiology: the legacy of Luigi Galvani. Brain Res. Bull. 46, 381-407. doi: 10.1016/s03619230(98)00026-4

Rash, J. E., Curti, S., Vanderpool, K. G., Kamasawa, N., Nannapaneni, S., Palacios-Prado, N., et al. (2013). Molecular and functional asymmetry at a vertebrate electrical synapse. Neuron 79, 957-969. doi: 10.1016/j.neuron.2013. 06.037

Rash, J. E., Staines, W. A., Yasumura, T., Patel, D., Furman, C. S., Stelmack, G. L., et al. (2000). Immunogold evidence that neuronal gap junctions in adult rat brain and spinal cord contain connexin-36 but not connexin-32 or connexin-43. Proc. Natl. Acad. Sci. U S A 97, 7573-7578. doi: 10.1073/pnas.97. 13.7573

Robertson, J. D. (1963). The occurrence of a subunit pattern in the unit membranes of club endings in mauthner cell synapses in goldfish brains. J. Cell Biol. 19, 201-221. doi: 10.1083/jcb.19.1.201

Robertson, J. D., Bodenheimer, T. S., and Stage, D. E. (1963). The ultrastructure of mauthner cell synapses and nodes in goldfish brains. J. Cell Biol. 19, 159-199. doi: $10.1083 /$ jcb.19.1.159

Sheng, M., Sabatini, B. L. and Sudhof, T. (2012). The Synapse, eds M. Sheng, B. L. Sabatini, and T. Südhof (New York, NY: Cold Spring Harbor Laboratory Press).

Skerrett, I. M., and Williams, J. B. (2017). A structural and functional comparison of gap junction channels composed of connexins and innexins. Dev. Neurobiol. 77, 522-547. doi: 10.1002/dneu.22447

Söhl, G., Maxeiner, S., and Willecke, K. (2005). Expression and functions of neuronal gap junctions. Nat. Rev. Neurosci. 6, 191-200. doi: 10.1038/nrn1627
Sohn, E. (2003). "Electricity's spark of life," in Sci. News Students 1. Available online at: www.sciencenewsforstudents.org

Thompson, R. J., Jackson, M. F., Olah, M. E., Rungta, R. L., Hines, D. J., Beazely, M. A., et al. (2008). Activation of Pannexin-1 hemichannels augments aberrant bursting in the hippocampus. Science 322, 1555-1559. doi: $10.1126 /$ science. 1165209

Van der Goes van Naters, W. (2013). Inhibition among olfactory receptor neurons. Front. Hum. Neurosci. 7:690. doi: 10.3389/fnhum.2013.00690

Verselis, V. K., Ginter, C. S., and Bargiello, T. A. (1994). Opposite voltage gating polarities of two closely related connexins. Nature 368, 348-351. doi: $10.1038 / 368348 \mathrm{a} 0$

Vroman, R., Klaassen, L. J., and Kamermans, M. (2013). Ephaptic communication in the vertebrate retina. Front. Hum. Neurosci. 7:612. doi: 10.3389/fnhum.2013. 00612

Watanabe, A. (1958). The interaction of electrical activity among neurons of lobster cardiac ganglion. Jpn. J. Physiol. 8, 305-318. doi: 10.2170/jjphysiol. 8.305

Weiss, S., and Faber, D. S. (2010). Field effects in the CNS play functional roles. Front. Neural Circuits 4:15. doi: 10.3389/fncir.2010.00015

Weiss, S. A., Preuss, T., and Faber, D. S. (2008). A role of electrical inhibition in sensorimotor integration. Proc. Natl. Acad. Sci. U S A 105, 18047-18052. doi: $10.1073 /$ pnas.0806145105

Conflict of Interest Statement: The authors declare that the research was conducted in the absence of any commercial or financial relationships that could be construed as a potential conflict of interest.

Copyright (c) 2018 Faber and Pereda. This is an open-access article distributed under the terms of the Creative Commons Attribution License (CC BY). The use, distribution or reproduction in other forums is permitted, provided the original author(s) and the copyright owner(s) are credited and that the original publication in this journal is cited, in accordance with accepted academic practice. No use, distribution or reproduction is permitted which does not comply with these terms. 